\title{
Evaluación por imágenes del diafragma en el niño
}

\author{
LIZBET PÉREZ M.*
}

\section{Image evaluation of diaphragm in children}

The anatomy, embriology and functions of the neonate's diaphragm, as well as its anatomical and functional oddities were reviewed. And, in a deeper way, imaging studies were also reviewed; these have an important role in functional and anatomic evaluation of the diaphragm, each one with its own advantages and limitations. Chest $X$-rays allow an anatomic two dimensional evaluation of the diaphragm and constitutes the first approach in the study of diaphragm pathology in children; hence, the normal anatomy and the most common pathological signs are reviewed. Digestive tube studies using contrast media still are the best choice for diagnosis of hiatal hernia and of herniation through the foramen of Morgagni, where the colon is ascended. Ultrasound use is highlighted for the evaluation of diaphragmatic motility, as well as some of its advantages over fluoroscopy, which is and has been the method of choice in the diagnosis of diaphragmatic paralysis in children. Multiplanar images are the most complete method for the anatomic evaluation of the diaphragm, since they show its spatial orientation and allow the detailed evaluation of those pahologies where the anatomy is altered, such as diaphragmatic hernias, trauma and tumors.

Key words: Diaphragm, diaphragmatic motility, diaphragm ultrasound, diaphragmatic paralysis, eventration, diaphragmatic hernia, hiatal hernia.

\section{Resumen}

Revisamos la embriología, anatomía y funciones del diafragma, sus particularidades anatómicas y funcionales en los neonatos y, en forma más profunda, los estudios por imágenes, que en la actualidad tienen un importante rol en su evaluación anatómica y funcional, cada uno de ellos con sus ventajas y limitaciones. La radiografía de tórax permite una evaluación anatómica en dos planos del diafragma y constituye la primera aproximación en el estudio de la patología del diafragma en los niños, por lo que se describe la anatomía normal y los signos de las patologías más frecuentes. Los estudios contrastados del tubo digestivo siguen siendo de elección para el estudio de las hernias hiatales y hernias de Morgagni en donde está ascendido el colon. Destacamos el uso del ultrasonido en la evaluación de la motilidad diafragmática, y algunas de sus ventajas sobre la fluoroscopia, que es y ha sido el método de elección en el diagnóstico de la parálisis diafragmática en los niños. Las imágenes multiplanares son un método más completo en la evaluación anatómica del diafragma, muestran mejor su orientación espacial y permiten la evaluación detallada de las patologías donde la anatomía está alterada, como hernias diafragmáticas congénitas, trauma y tumores. hiatal.

Palabras clave: Diafragma, ultrasonido, parálisis difragmática, hernia diafragmática, hernia

\section{Introducción}

El diafragma es "la división músculo-fibrosa que separa la cavidad torácica de la cavidad abdominal. Su contracción aumenta el volumen de la cavidad torácica ayudando a la inspiración". ${ }^{1}$
El diafragma es considerado el principal músculo respiratorio a cualquier edad, y es el sostén principal de la ventilación en el recién nacido ${ }^{2}$. Los estudios por imágenes tienen un importante rol en su evaluación anatómica, además de su evaluación funcional.

* Radióloga Pediatra. Hospital de Niños Roberto del Río. Hospital Clínico de la Universidad de Chile. Clínica Alemana de Santiago. Clínica INDISA. 
En este artículo pretendemos dejar planteados los aportes y limitaciones de las diferentes técnicas de imágenes en el estudio de las alteraciones de la motilidad diafragmática y las hernias diafragmáticas.

\section{Embriología}

El diafragma se forma a partir de cuatro precursores (Figura 1a):

- Septum transversum, que da origen al tendón central.

- Miocitos de miotomas cervicales III, IV, V, de los cuales se originan la fibras musculares periféricas.

- Membranas pleuroperitoneales, que dan origen a la mayor parte del componente muscular del diafragma.

- Mesenterio esofágico, que da origen a la porción media del diafragma, incluida la crural ${ }^{3}$.

\section{Anatomía}

Comprende tres partes (Figura 1b):

- Tendón central: Estructura fibrosa inelástica que sirve de origen a las fibras musculares, con su vértice situado en el esternón. Tiene forma bilobulada, determinando una cúpula a cada lado.

- Diafragma anterolateral o costal: Se origina en el tendón central, con fibras musculares orientadas radialmente hacia anterior, para insertarse en el apéndice xifoides (fibras esternales) y lateralmente en la porción interna de las costillas 10 a 12 y cartílagos costales correspondientes (fibras costales). Se divide en dos partes, hemidiafragma derecho e izquierdo. Cada parte puede funcionar en forma casi independiente de la otra.

- Diafragma crural: Se origina del tendón central, la disposición de las fibras es más compleja, se inserta en las tres primeras vértebras lumbares y costillas inferiores. En el hiato esofágico las fibras crurales se entrecruzan para formar parte del esfínter esofágico inferior.
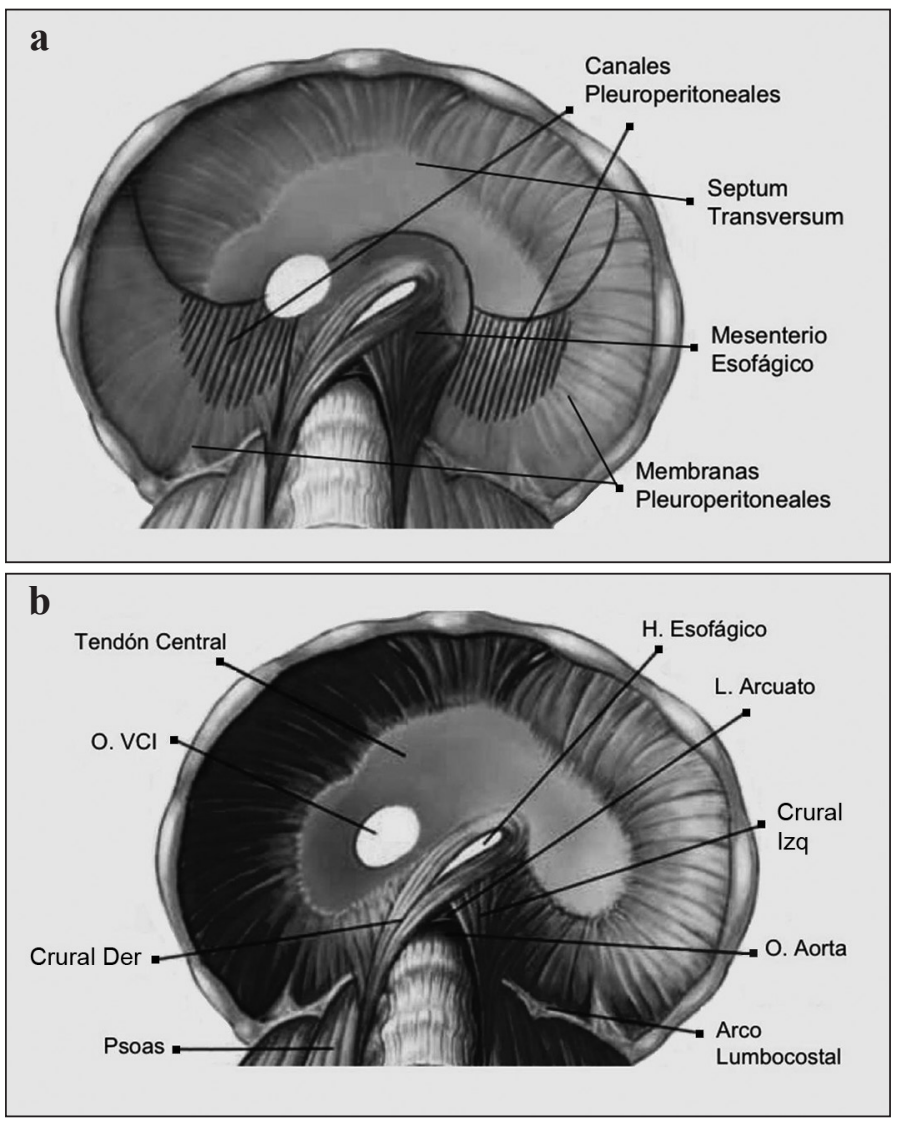

Figura 1 a, b. Esquema de la embriología (a) y anatomía (b) del diafragma, modificado de: http://www.vesalius.com/graphics/archive/ archtn_gallery.asp?keyl $=$ embryology\&key2 $=$ diaphragm $\&$ key $3=n o$. $\mathrm{H}$ : hiato; L: ligamento; $\mathrm{O}$ : orificio; VCI: vena cava inferior.

Orificios del Diafragma (Figura 1b): 1) Para la vena cava inferior la altura de T8-T9; 2) Hiato esofágico a la altura de $\mathrm{T} 10 ; 3)$ Para la aorta a la altura de T12,

Inervación: La inervación motora y sensitiva proviene de los nervios frénicos izquierdo y derecho. Cada mitad del diafragma está inervada por su propio nervio.

Irrigación: El borde costal del diafragma está irrigado por las 5 arterias intercostales inferiores y las subcostales. La principal masa de fibras está irrigada en su superficie abdominal por las arterias frénicas inferiores derecha e izquierda, que nacen de la porción abdominal de la aorta descendente (Figura 2). Otras arterias que intervienen en la irrigación del diafragma son las arterias pericardio-frénicas, músculo-frénicas que son ramas de la arteria torácica interna, y las arterias frénicas superiores que provienen de la porción torácica de la aorta descendente 3,4 .

\section{Funciones del diafragma}

Inspiración: Es la función principal, desplazando volumen e inflando el pulmón a través de la generación de presión pleural negativa o sub atmósferica. Esto lo logra al contraerse, acortando sus fibras y produciendo un descenso relativo de la 

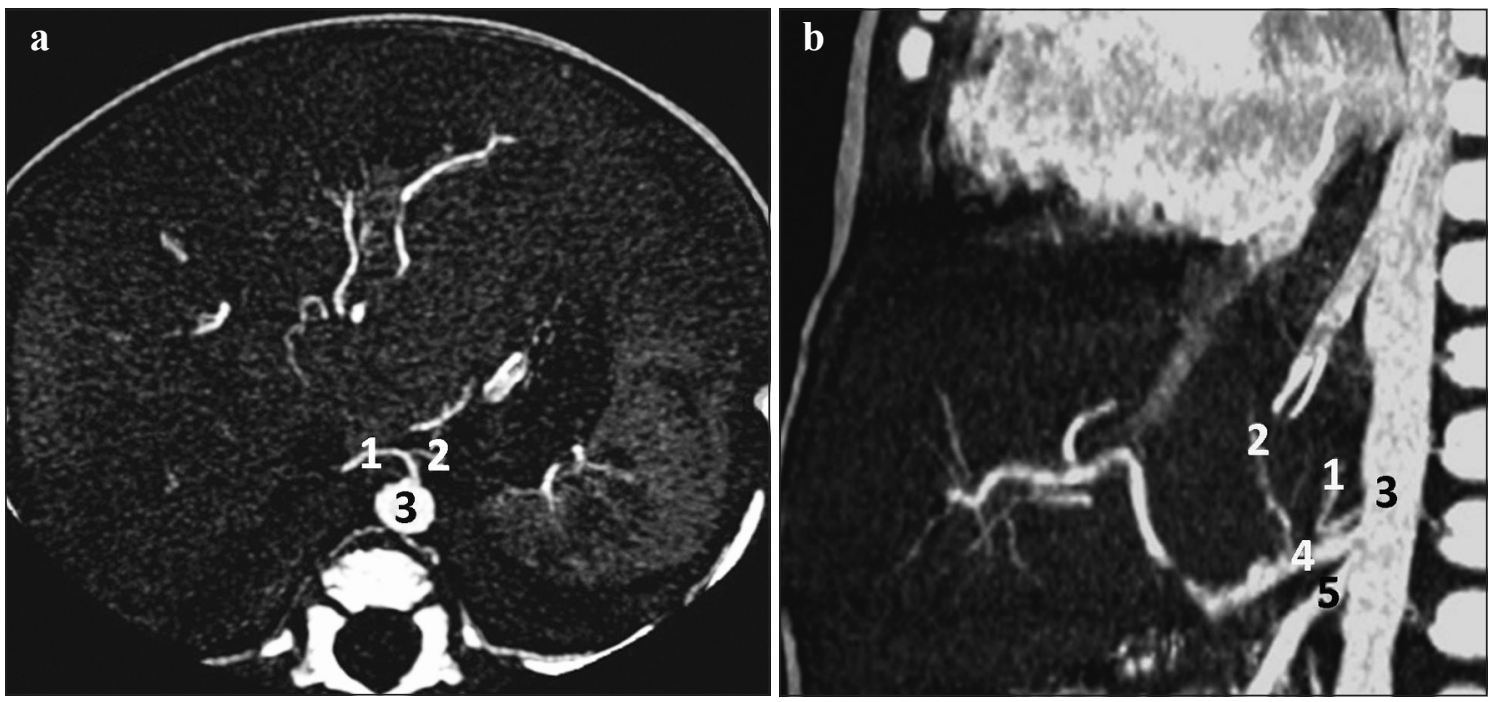

Figura 2. Angio-TC de Tórax. Lactante masculino, 1 año 3 meses con Cardiopatía Congénita. Se muestra el origen de las arterias frénicas inferiores. 1: Arteria frénica inferior derecha. 2: Arteria frénica inferior izquierda. 3: Aorta descendente abdominal. 4: Tronco celíaco. 5: Arteria mesentérica superior.

cúpula diafragmática respecto a sus inserciones costales. En la inspiración profunda el mayor descenso de las cúpulas, es por debajo del centro tendinoso, que puede deprimirlo de T8 a T92.

Esfuerzo abdominal: Tiene un papel importante en el control de la presión intraabdominal ya que opone resistencia al movimiento ascendente del contenido del abdomen cuando se contraen los músculos abdominales a fin de generar actos expulsivos. Esta misma acción es importante para sostener la región lumbar de la columna al levantar objetos pesados ${ }^{2}$.

\section{Particularidades del diafragma en los neonatos:}

El diafragma en el neonato se diferencia del adulto en:

- Inserción a la caja torácica: Los neonatos presentan un gran ángulo de inserción de las fibras musculares en la pared lateral del tórax, lo cual limita la zona de aposición. Como resultado, la mayor parte del movimiento del diafragma neonatal es en la porción posterior, en contraste con el movimiento a modo de pistón del diafragma adulto (Figura 3).

- Forma aplanada: Debido a que el diafragma neonatal es más plano que el adulto, la presión máxima transdiafragmática generada por la contracción es menor (Figura 3).

- Composición de fibras: Diafragmas de adultos y neonatales difieren en la proporción relativa de las fibras tipo I y II del músculo, lo cual afecta su capacidad para resistir la fatiga. Fibras de tipo I generan un bajo nivel de fuerza, pero son relativamente resistentes a la fatiga. Fibras de tipo II generan un alto nivel de la fuerza, pero se fatigan con facilidad. $\mathrm{La}$ proporción de fibras resistentes a la fatiga es menor en el diafragma neonatal $(25 \%$ versus $55 \%$ ) en comparación con el adulto.

- Posición del cuerpo: El diafragma es menos eficiente en el decúbito que es la posición en que se encuentran los neonatos.

Como resultado de estas particularidades anatómicas y funcionales el consumo de oxígeno para realizar el trabajo ventilatorio en el neonato es mayor $(6-8 \mathrm{~mL} / \mathrm{kg} / \mathrm{min})$ que en lactantes (3-4 $\mathrm{mL} / \mathrm{kg} / \mathrm{min})$ y que en adultos $(2-3 \mathrm{~mL} / \mathrm{kg} /$ min). La eficacia de la ventilación es aún menor en el prematuro, con lo que el consumo de oxígeno puede ser hasta tres veces superior al del adulto. ${ }^{2}$

\section{Imágenes para la evaluación del diafragma}

El estudio anatómico puede ser efectuado con radiografía de tórax (RxTx), fluoroscopía, ultrasonido (US), tomografía computarizada (TC) y resonancia magnética (RM); en tanto para el estudio funcional son útiles la fluoroscopía, ultrasonido y resonancia magnética.

\section{Radiografía de tórax}

Permite una evaluación anatómica, estática y en dos planos. La posición del diafragma va a depender del grado de inspiración-espiración en que se tome la proyección, lo cual es variable en los niños. Este método constituye casi siempre la 

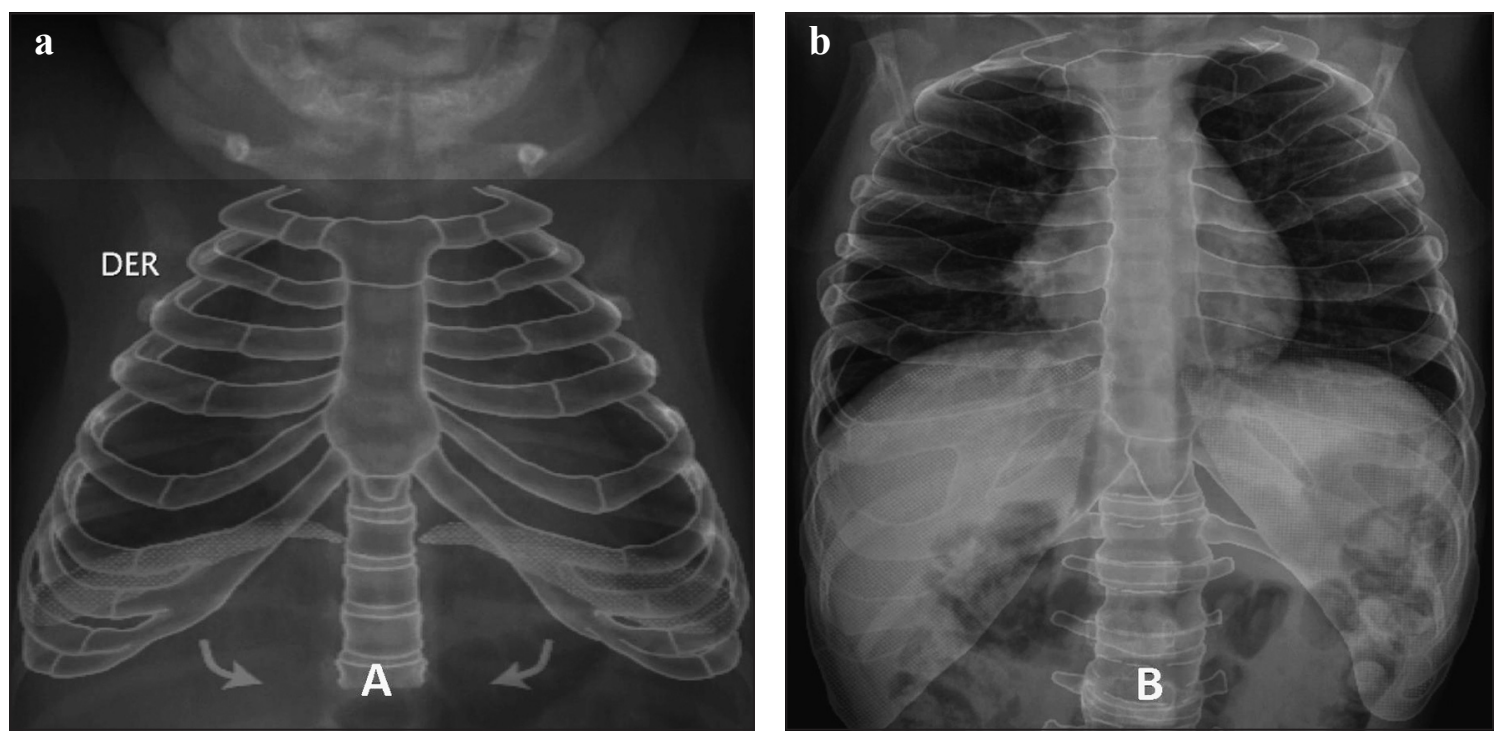

Figura 3 a, b. (a) Esquema del diafragma de un recién nacido, donde se aprecia el gran ángulo de inserción en la caja torácica, determinando una menor zona de aposición y una forma aplanada. (b) Esquema del diafragma de un niño mayor, el ángulo de inserción en la caja torácica es menor, con una mayor zona de aposición y una forma más curva, lo que le permite movimiento en pistón con más eficiencia en la presión que genera.

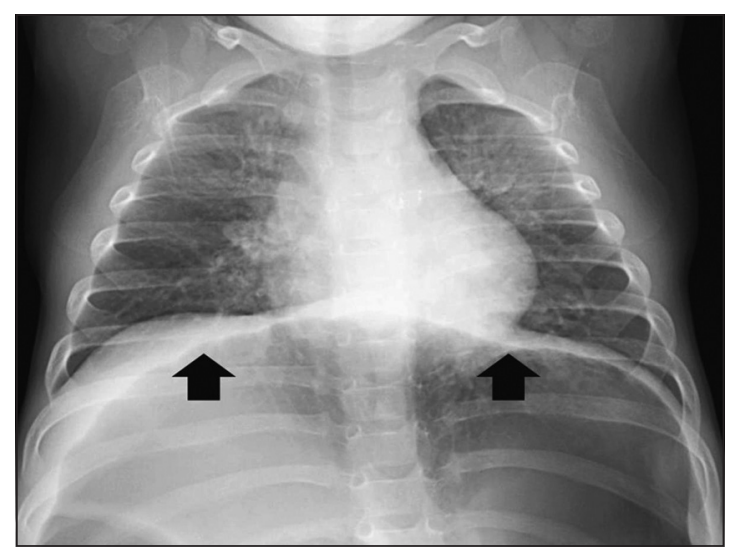

Figura 4. Radiografía de tórax AP. Lactante con neumoperitoneo. Se marca con flechas negras el borde inferior del diafragma, habitualmente no visible, al contrario del borde superior que sí lo es, por estar en contacto con los pulmones con aire.

primera aproximación en el estudio de patología diafragmática en niños, por tanto debemos conocer la anatomía normal en las proyecciones más usadas $^{4,5}$.

En la RxTx la cara superior del diafragma es fácilmente identificable en las proyecciones anteroposterior (AP) y lateral (L) por la presencia de tejido pulmonar con aire por encima del diafragma. Sin embargo, su cara inferior se mezcla con la densidad de los tejidos blandos subdiafragmáticos, y sólo es posible visualizarla cuando hay aire subdiafragmático en los casos de neumoperitoneo (Figura 4).

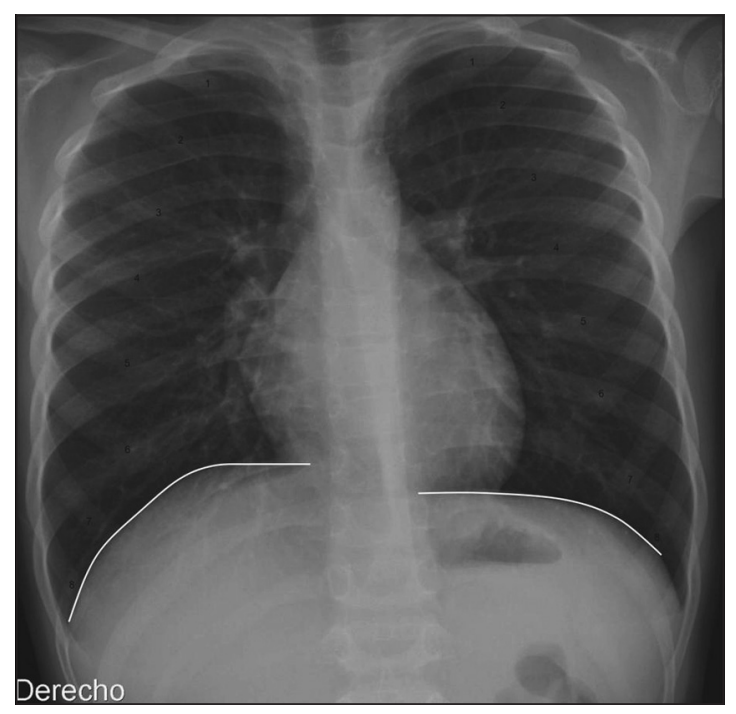

Figura 5: Radiografía de tórax AP de un escolar normal. La posición de las cúpulas diafragmáticas es variable, según el grado de inspiración. Casi siempre la derecha está a la altura del sexto arco costal anterior y la izquierda un espacio intercostal más abajo.

En la proyección AP de los lactantes y niños pequeños, la cúpula derecha del diafragma se proyecta en torno al nivel del sexto arco costal anterior y la cúpula izquierda es generalmente un espacio intercostal caudal a la derecha (Figura 5). En la proyección lateral, la parte anterior del hemidiafragma izquierdo está opacificada por la silueta cardíaca, pero el hemidiafragma derecho se ve por completo (Figura 6). 


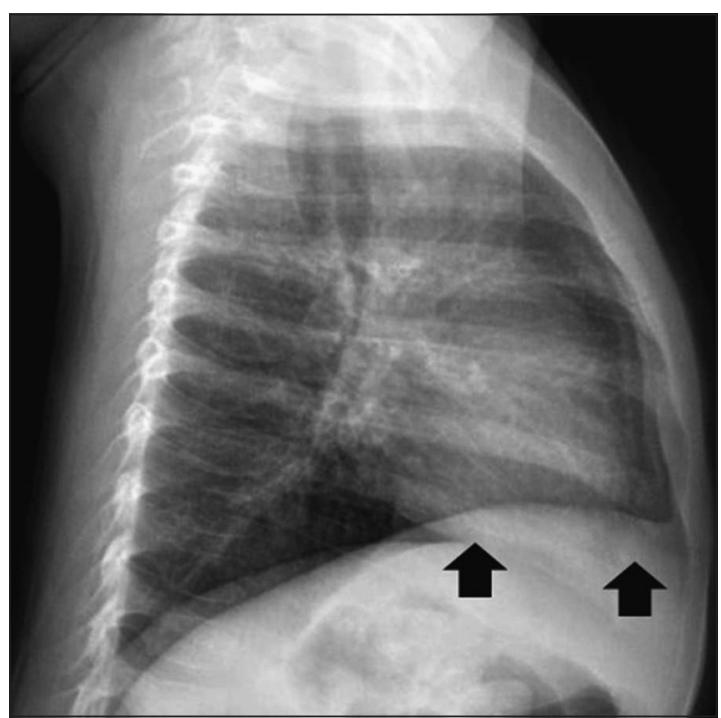

Figura 6. Radiografía de tórax lateral de un lactante normal. En la proyección lateral, la parte anterior del hemidiafragma izquierdo está opacificada por la silueta cardíaca (flechas negras), el hemidiafragma derecho se ve por completo.

Parálisis diafragmática: Se aprecia ascenso anormal del diafragma. En el lado de la parálisis también podemos ver con mayor frecuencia atelectasias y condensaciones en el parénquima. Estos hallazgos tienen poca sensibilidad y especificidad $^{2,4}$ (Figura 7).

Eventración completa: La RxTx muestra la elevación del diafragma afectado y la desviación del mediastino hacia el lado contralateral ${ }^{2,4,11}$ (Figura 8).

Eventración focal: Hallazgo incidental en la RxTx, es más frecuente en el aspecto anteromedial de la cúpula diafragmática derecha ${ }^{4}$.

Hernia diafragmática congénita de Bochdalek: La Rx tóraco-abdominal suele ser diagnóstica, observándose las asas intestinales herniadas al tórax, con ausencia de gas en el abdomen y un abdomen excavado en la proyección lateral (Figura 9). También se puede ver un hemitórax opaco, con desviación del mediastino hacia el lado contra lateral ${ }^{4,12,14}$ (Figura 10).

Hernia diafragmática de Morgagni: La proyección lateral es diagnóstica, observándose la herniación anterior, en el espacio retroesternal de asas intestinales. También se puede ver en esta misma ubicación una opacidad con densidad de partes blandas, que a veces es intermitente, puede corresponder a hígado herniado ${ }^{4,12,14}(\mathrm{Fi}$ gura 11).

Hernia hiatal: En la RxTx puede ser vista como una masa sólida retrocardiaca, con aire o con nivel hidroaéreo (Figura 12a). El estudio ba-
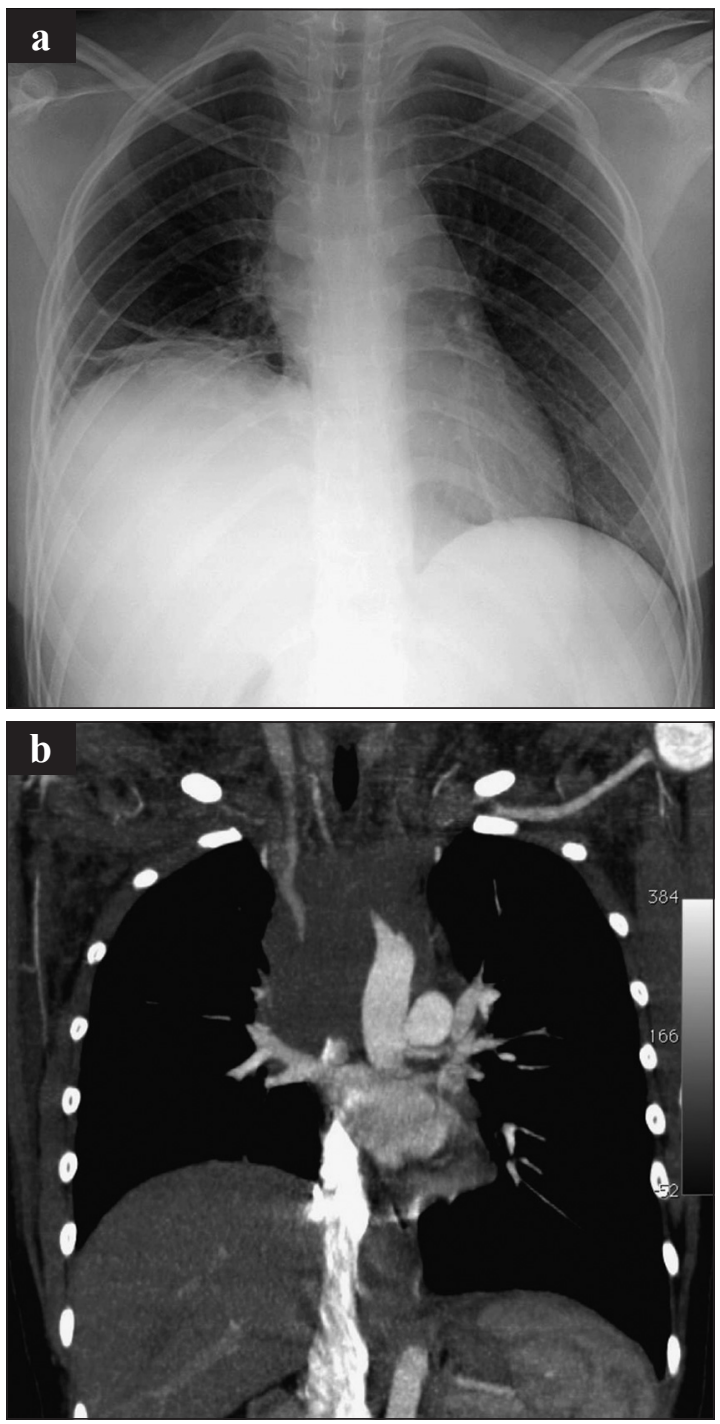

Figura 7 a, b. Radiografía de tórax AP (a) y TC (b). Niña de 13 años, con Linfoma Anaplásico mediastínico, presenta invasión del nervio frénico derecho, con parálisis del hemidiafragma derecho. Se aprecia un ascenso anormal del hemidiafragma derecho y algunas atelectasias subsegmentarias basales en el lado afectado.

ritado simple del tubo digestivo superior, permite un diagnóstico definitivo ${ }^{4,12,14}$ (Figura 12b).

\section{Fluoroscopia}

Clásicamente ha sido utilizada para la evaluación de la motilidad del diafragma. En esta técnica, el movimiento del diafragma se puede evaluar con el paciente en la posición decúbito, de pie y en proyecciones AP y lateral. La exploración de rutina se realiza durante la respiración tranquila y la respiración profunda. En estos casos el operador realiza una evaluación comparativa del movimiento de las cúpulas, de la excursión de 


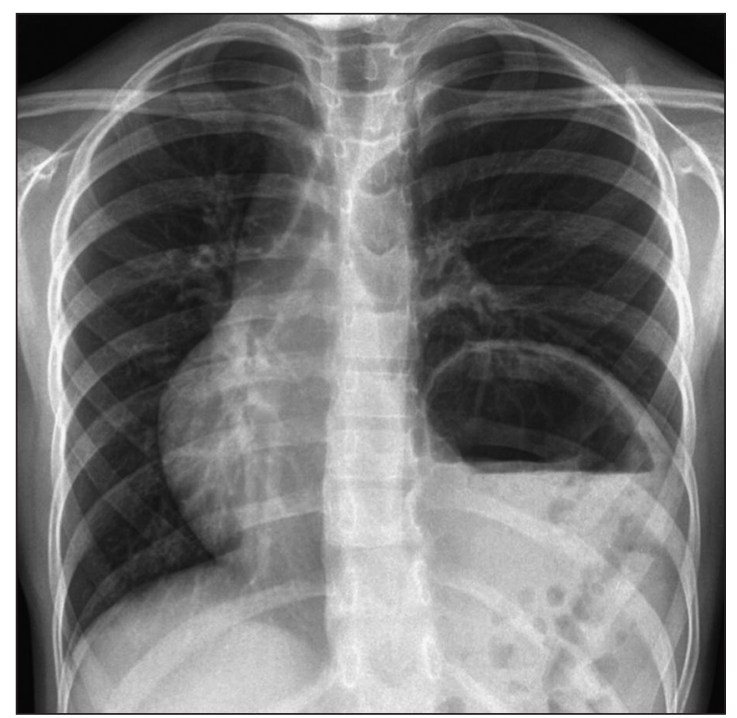

Figura 8. Radiografía de tórax AP. Niño de 9 años, asintomático. Eventración completa del hemidiafragma izquierdo. Se aprecia ascenso anormal del hemidiafragma y desviación del mediastino hacia el lado contralateral.

una cúpula individual, y de los movimientos del mediastino ${ }^{2,4}$. Actualmente, la videofluoroscopía permite grabar ciclos respiratorios consecutivos durante pocos segundos, para posteriormente analizar el vídeo, lo cual evita largas exposiciones a radiaciones ionizantes.

Signos fluoroscópicos en el diagnóstico de la parálisis del diafragma ${ }^{2,4}$ :

1. Elevación del diafragma paralizado por sobre el rango normal durante la inspiración.

2. Movimiento disminuido, ausente o paradojal durante la respiración tranquila.
3. Desplazamiento del mediastino hacia el lado contralateral durante la inspiración. (bamboleo mediastinal).

4. Movimiento paradojal bajo condiciones de carga incrementada como el Test Sniff ("olfateo").

Hay limitaciones y desventajas de la fluoroscopía en la evaluación del diafragma en niños que son necesarias conocer ${ }^{4,6,7}$. La evaluación fluoroscópica AP del diafragma incluye la visualización del tercio anterior del diafragma que es la porción menos móvil, corriendo el riesgo de una interpretación errónea de parálisis diafragmática bilateral. La evaluación del movimiento del diafragma no es cuantificable. No se visualiza el músculo propiamente tal, no pudiendo determinarse su grosor y características. Hay uso de radiaciones ionizantes, lo que es contraproducente en aquellos pacientes con patologías crónicas que requieren varias evaluaciones en el curso de la historia natural de la enfermedad. Requiere transporte de pacientes a la sala de fluoroscopia, lo que muchas veces resulta difícil por la condición clínica del paciente.

\section{Ultrasonido (US)}

Permite la evaluación anatómica y funcional del diafragma, usando su Modo B y su Modo M respectivamente. Los pacientes son examinados en respiración espontánea. En los niños que están en ventilación mecánica, el ventilador se desconecta temporalmente para obtener trazados durante la respiración espontánea. Con un abordaje transversal oblicuo subxifoídeo en línea media, se pueden visualizar ambas cúpulas juntas, pudiendo evaluar y comparar sus movimientos en tiempo real (Figura 13). Las cúpulas individuales pueden
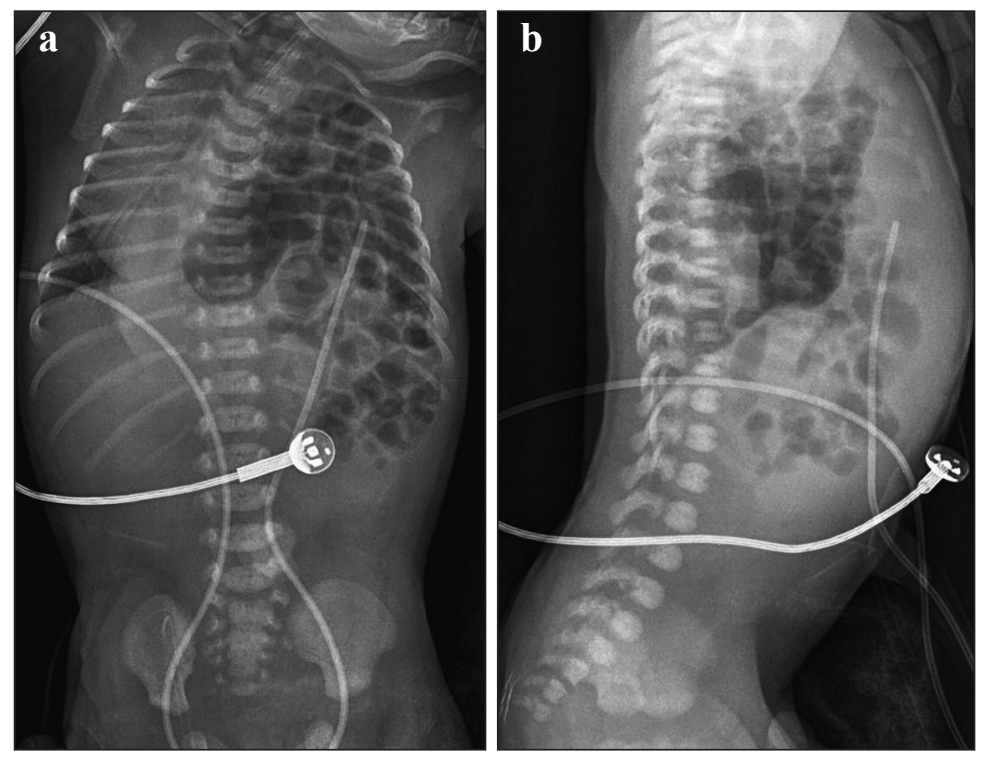

Figura 9 a, b. Radiografía tóracoabdominal AP (a) y lateral (b). Recién nacido, diagnóstico prenatal de hernia diafragmática congénita izquierda tipo Bochdalek. Se aprecian múltiples imágenes aéreas ocupando el hemitórax izquierdo, que corresponden a las asas intestinales herniadas al tórax, desviación del mediastino hacia el lado contra lateral, ausencia de gas en el abdomen y abdomen excavado en la proyección lateral. 
ser evaluadas en abordajes subcostal o intercostal en los planos parasagital y coronal entre las líneas axilares anterior y medias ${ }^{4,6-9}$ (Figura 14).

Modo B: Es usado para el estudio anatómico del diafragma y permite: Evaluar la continuidad de sus fibras. Evaluación morfométrica del dia- fragma que incluye el grosor tanto en relajación como durante maniobras.

Las cúpulas del diafragma actúan como un reflector especular de ondas de US, por lo que se ven como una gruesa línea ecogénica (Figura 13). Las inserciones costales y la porción crural
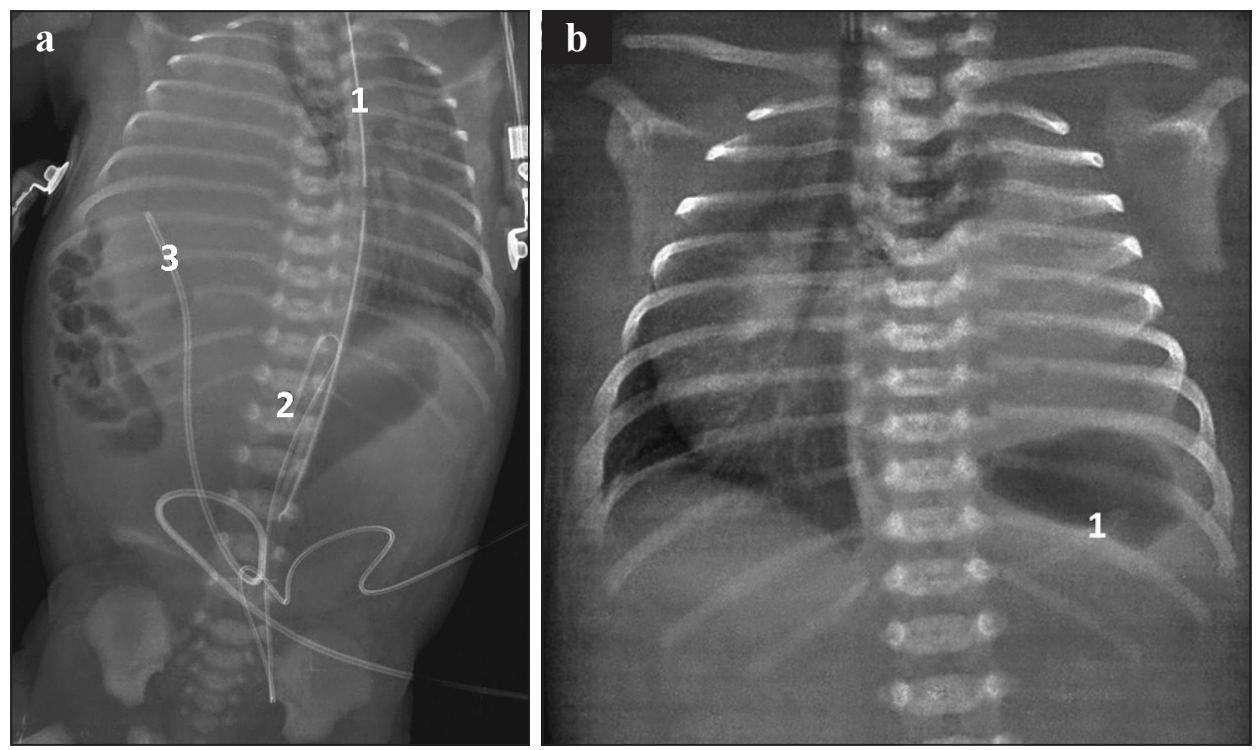

Figura 10 a, b. Radiografía tóraco-abdominal AP (a). Recién nacido, diagnóstico prenatal de Hernia Diafragmática Congénita Derecha. Se aprecia una opacidad difusa del hemitórax derecho que provoca desplazamiento de las estructuras mediastínicas al lado contralateral, corresponde al hígado herniado al tórax, imágenes aéreas en la periferia de la base derecha corresponden a asas intestinales herniadas en conjunto con el hígado. (1) Sonda de alimentación con extremo en estómago; (2) Catéter arterial umbilical en posición baja en la aorta descendente abdominal, con extremo doblado; (3) Catéter venoso umbilical que sigue el trayecto de la vena umbilical a vena porta izquierda, como en este caso el hígado está herniado al tórax el extremo del catéter se encuentra intratorácico; b: Radiografía de tórax AP portátil. Recién nacido, con diagnóstico prenatal de hernia diafragmática congénita izquierda. Se aprecia una opacidad difusa del hemitórax izquierdo con desplazamiento de la vía aérea y de las estructuras mediastínicas al lado contralateral. En este caso la RxTx fue tomada muy precozmente, por lo que sólo hay aire en la cámara gástrica (1) que tiene el extremo de una sonda de alimentación en su lumen.
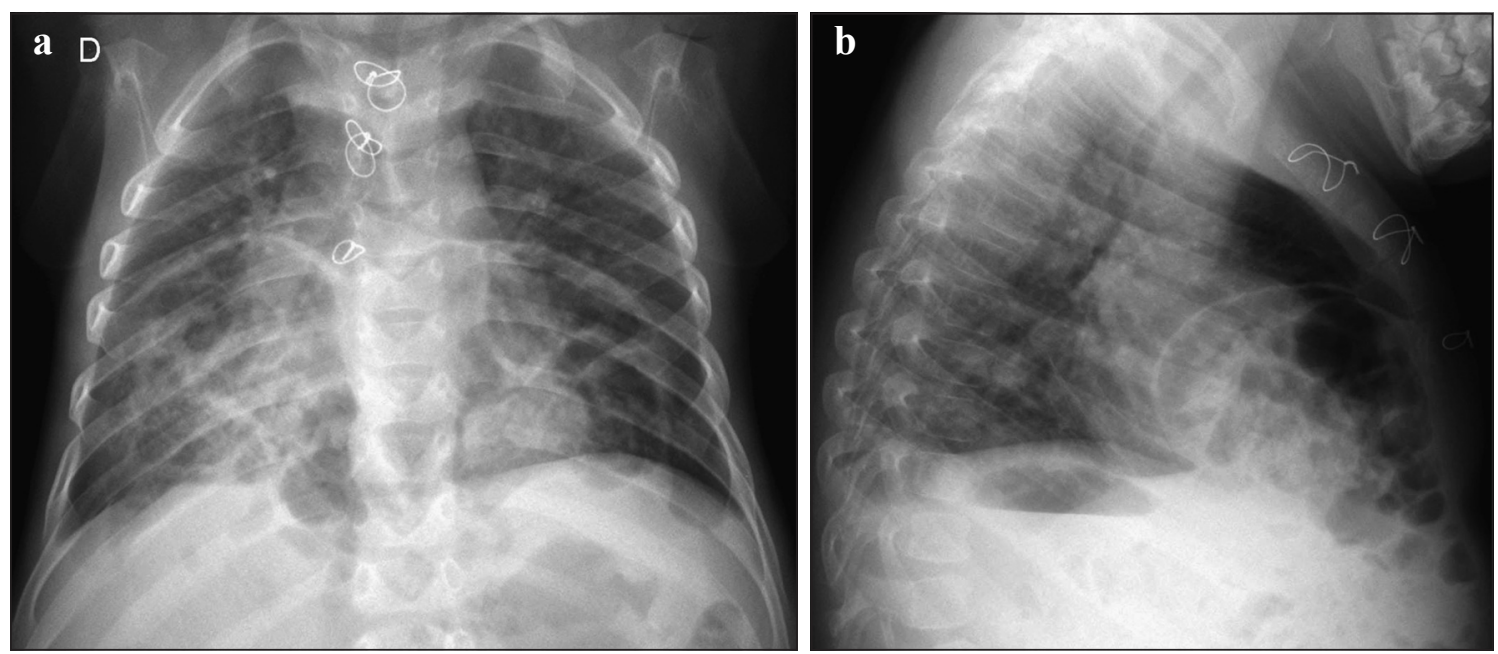

Figura 11 a, b. Radiografía de tórax AP (a) y lateral (b). Niño de 17 meses, Síndrome Down, antecedente de Cardiopatía Congénita operada. Actualmente con Síndrome bronquial obstructivo (SBO). En la proyección AP se aprecian imágenes aéreas en la base del tórax, en el mediastino central, la proyección lateral es diagnóstica ya que se corrobora el ascenso de asas de colon al tórax en el espacio retroesternal, lo que corresponde a Hernia de Morgagni, frecuente de ver en los niños con S. de Down. 

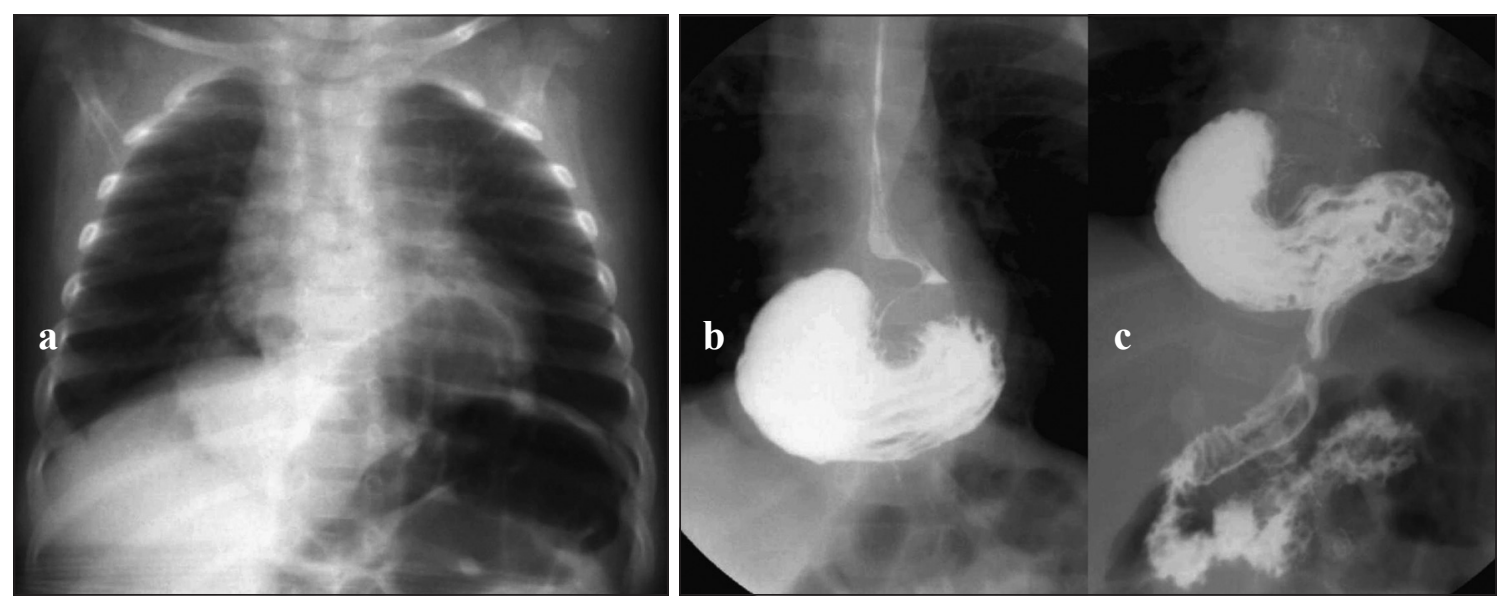

Figura 12 a-c. Radiografía de tórax AP (a) y lateral (b). Niña de 9 meses con SBO. En proyección AP se aprecia una imagen basal central, de densidad mixta, con opacidad a derecha de la columna y aérea a izquierda. En la proyección lateral corresponde a una imagen redondeada con aire de ubicación retrocardíaca, sugerente de Hernia Hiatal. c: Estudio baritado simple de esófago-estómago-duodeno. En este estudio se corrobora que la imagen visualizada en la RxTx corresponde al estómago herniado al tórax, con vólvulo parcial. AP: antero-posterior; SBO: síndrome bronquial obstructivo.

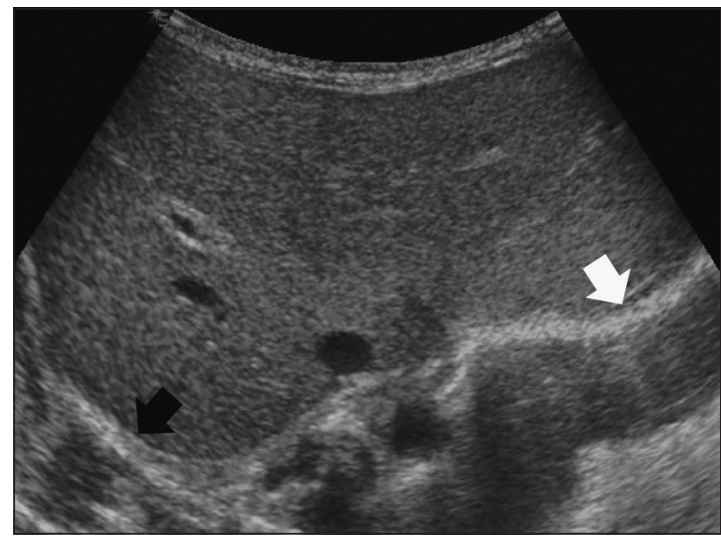

Figura 13. Ultrasonido del diafragma Modo B. Abordaje subxifoídeo transversal. Recién nacido con Cardiopatía Congénita operada. En esta evaluación se muestran ambos hemidiafragmas, pudiendo comparar su movimiento en tiempo real. Las cúpulas diafragmáticas se ven como una gruesa línea ecogénica. La cúpula derecha señalada con flecha negra y la izquierda con flecha blanca.

del diafragma también pueden ser visualizadas, sobre todo en lactantes y niños pequeños, como con una banda de tejido muscular hipoecogéni$\operatorname{co}^{4,6-9}$ (Figura 14).

Modo M: Usado para evaluar el movimiento del diafragma ya que durante la inspiración el diafragma se acerca al transductor lo que es grabado como un movimiento localizado, cuando se relaja en espiración y se mueve hacia cefálico, se aleja del transductor lo que queda representado como una inflexión. Permite una evaluación cuantitativa mediante el uso de dos parámetros: la dirección de movimiento y la amplitud de la excursión (Figura 15). No existen rangos normales por edad para la excursión del diafragma, el movimiento se considera normal si el diafragma se mueve hacia el transductor durante la inspiración, con una excursión de más de $4 \mathrm{~mm}$ y una diferencia en la excursión entre las cúpulas de menos de $50 \%{ }^{4,6-9}$ (Figura 16).

Las ventajas del US sobre la fluoroscopia para la evaluación anatómica y funcional del diafragma son las siguientes: su portabilidad, ya que puede usarse al lado de la cama del paciente; ausencia de radiación ionizante; permite la evaluación del movimiento en tiempo real; posibilita la visualización del músculo y de las estructuras por encima y por debajo del diafragma, lo que permite una caracterización anatómica y morfométrica; tiene la capacidad de cuantificar el movimiento del diafragma; al no ser invasivo ni ocupar radiaciones ionizantes puede ser usado en seguimiento de pacientes a largo plazo y en investigación.

Parálisis diafragmática: Excursión diafragmática inferior a $4 \mathrm{~mm}$, presencia de movimiento paradojal, y la diferencia de más del $50 \%$ entre las excursiones de los hemidiafragmas, demostrado en el modo M de US ${ }^{4,6}$ (Figura 16).

Hernias diafragmáticas: Puede ayudar en casos donde vísceras sólidas como el hígado están dentro de hernias de Morgagni y también hernias hiatales pueden ser diagnosticadas con ultrasonido, si bien este no es el método de elección para su evaluación (Figura 17). 

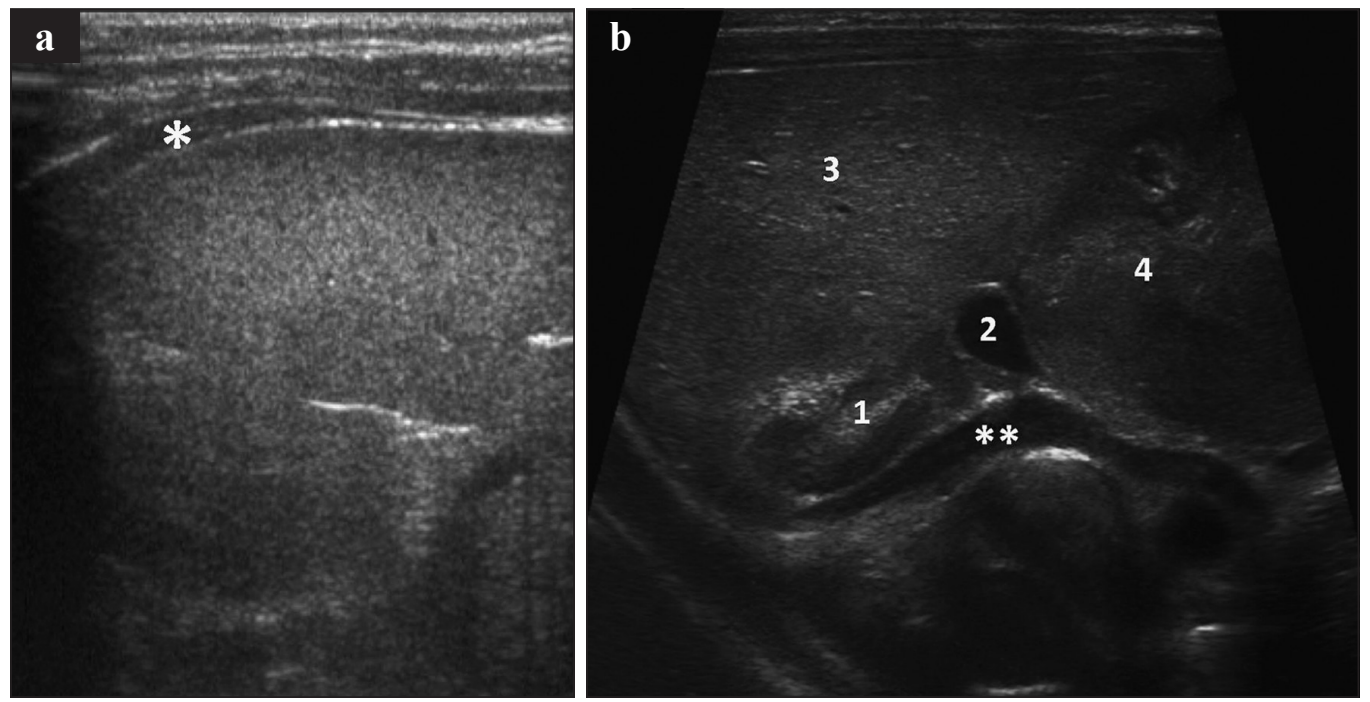

Figura 14 a, b. US del diafragma Modo B. a: Abordaje lateral izquierdo intercostal. recién nacido con cardiopatía congénita operada. Se visualiza el diafragma costal como una banda de tejido muscular hipoecogénico $(*)$. b: Abordaje lateral derecho subcostal. Recién nacido con diagnóstico de neuroblastoma de cadena ganglionar para-aórtica derecha. Se visualiza el diafragma crural derecho (**) mostrando la masa (4) por dentro de la porción crural, lo cual permite decir que es una masa intrabdominal. Se visualiza la suprarrenal derecha normal (1), la vena cava inferior (2) y el lóbulo derecho del hígado (3).

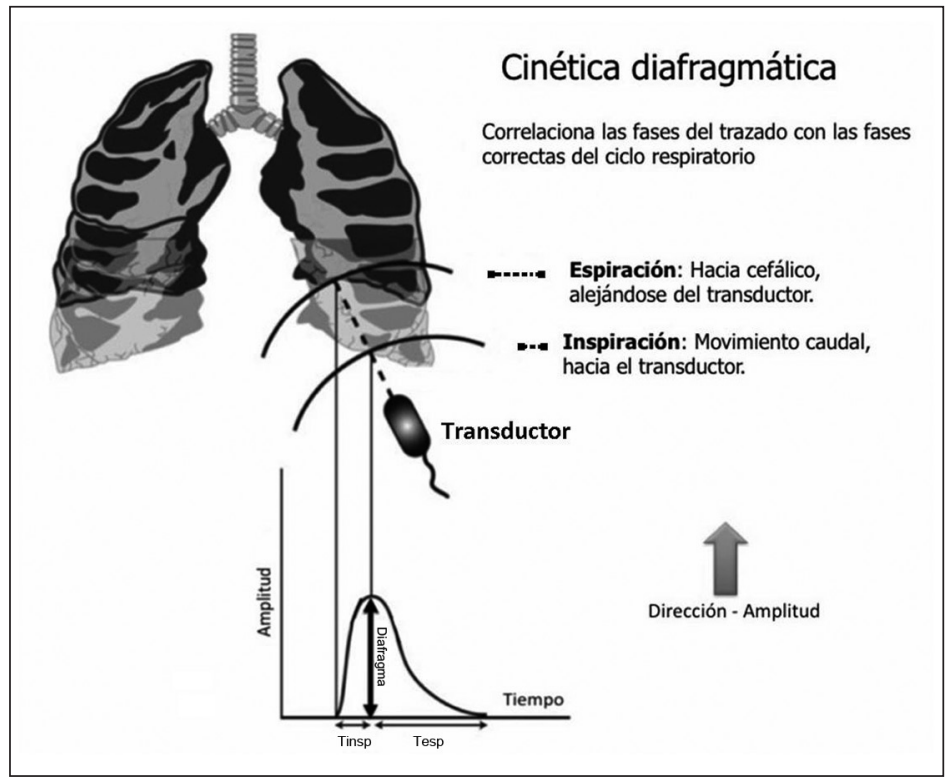

Figura 15. Esquema de la evaluación del movimiento del diafragma con Modo M. El diafragma se mueve hacia el transductor durante la inspiración. La distancia entre el fin de la espiración y el final de la inspiración es la excursión. (Modificado de referencia 7).

\section{Imágenes multiplanares}

Tomografia computada (TC): Por su capacidad multiplanar puede ser un excelente método para la evaluación anatómica del diafragma, es más fácil entender la orientación espacial del diafragma y permite una evaluación más detallada de las patologías donde está alterada la anatomía del diafragma, como las hernias diafragmáticas. La TC tiene la desventaja del uso de las radiaciones ionizantes. No tiene uso en la evaluación funcional del diafragma ${ }^{4}$.

Resonancia Magnética (RM): También tiene la ventaja de ser multiplanar, por lo que es igual a la TC para la evaluación anatómica del diafragma. La RM adicionalmente proporciona una excelente resolución de los tejidos blandos. El diafragma se aprecia como una lámina delgada de músculo que separa las cavidades torácica y 

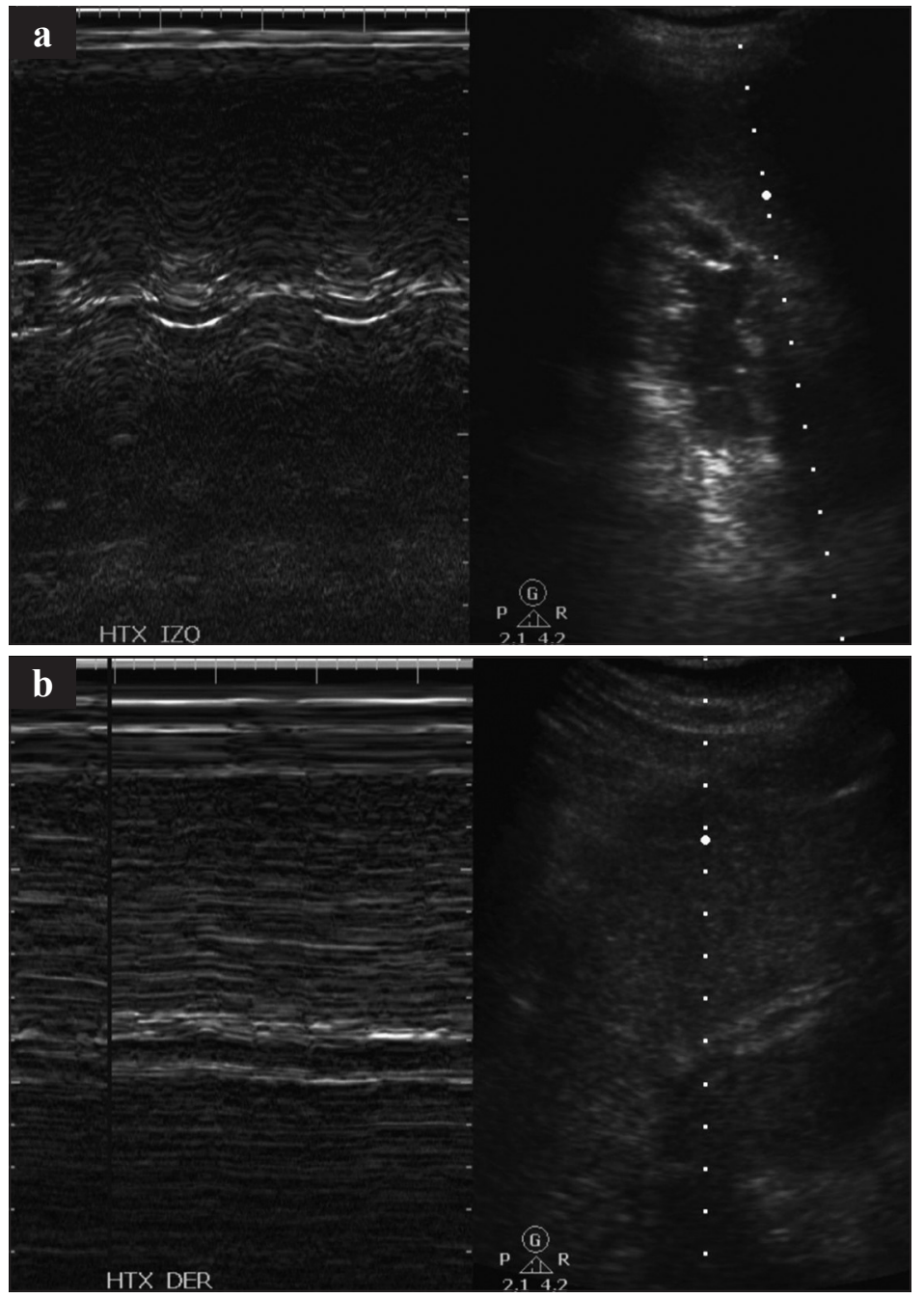

Figura 16 a, b. US Modo M. Abordaje lateral subcostal, a cada lado. Mismo caso de la figura 7. Niña de 13 años, con linfoma anaplásico mediastínico, invasión del nervio frénico derecho y parálisis del hemidiafragma derecho. La curva del hemidiafragma izquierdo (a) es de trazado normal, mientras la derecha (b) es plana, lo que corrobora la sospecha clínica y los hallazgos de las imágenes estáticas.
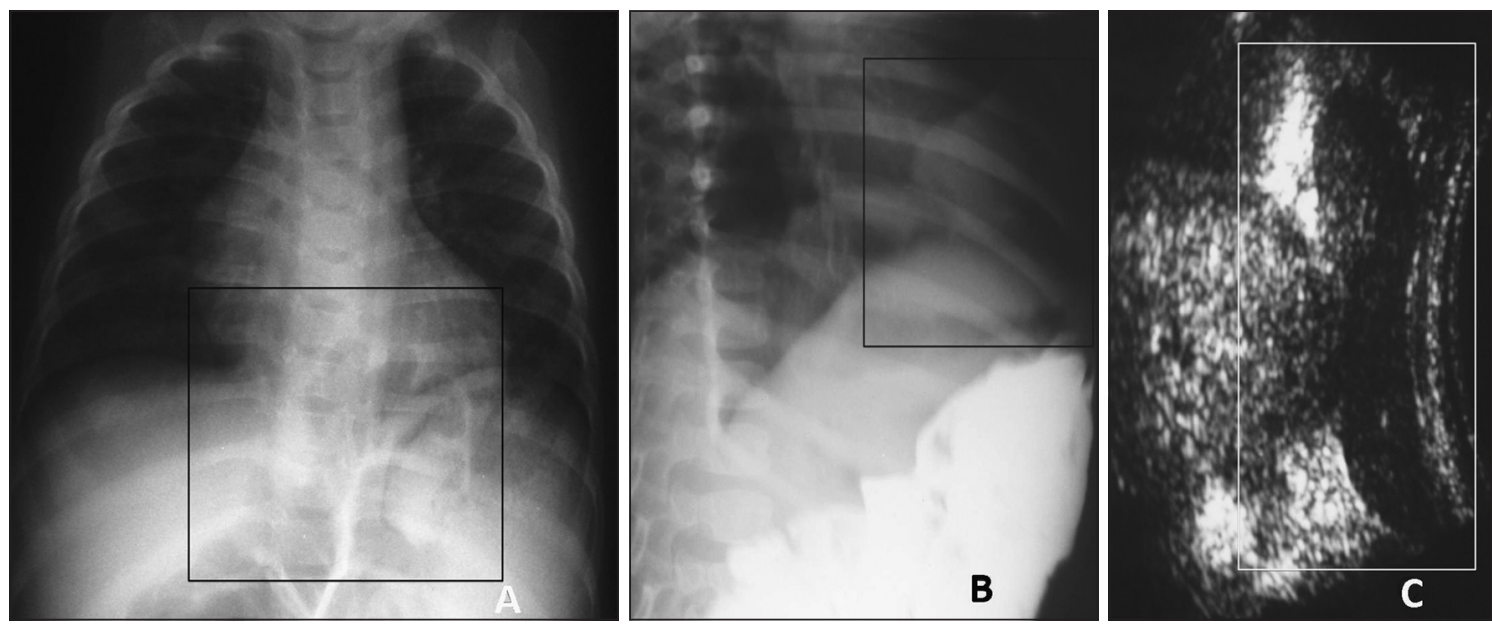

Figura 17 a-c. Niña de 1 año 9 meses. (a) RxTx AP muestra imágenes aéreas en la base del tórax, en el mediastino central, con aspecto de corresponder al colon herniado al tórax, posiblemente Hernia de Morgagni; b: Enema baritado de colon muestra que el colon está infradiafragmático, pero se aprecia una opacidad retroesternal; c: US muestra que parte del lóbulo izquierdo del hígado se encuentra ocupando el espacio retroesternal, herniado hacia el tórax, a través de un defecto anterior izquierdo del diafragma, hernia difragmática de Larrey (equivalente izquierdo de la Hernia de Morgagni). 
abdominal, tiene baja intensidad de señal relativa a la de otros músculos esqueléticos en todas las secuencias de $\mathrm{RM}^{4}$. Actualmente se ha estado usando secuencias de gradiente, secuencias dinámicas y cine RM en la evaluación de la función diafragmática, en cuanto a cuantificación de la excursión, sincronía y la velocidad del movimiento del diafragma ${ }^{15}$. La RM no ocupa radiaciones ionizantes, pero en casos de niños pequeños se requiere sedación o anestesia, lo cual aumenta los riesgos del examen.

Eventración: El estudio anatómico multiplanar puede corroborar la elevación del diafragma ya que permite visualización del diafragma intacto. Con la TC se puede identificar el grado de compresión del parénquima pulmonar subyacente. Sirven para el diagnóstico diferencial con otras patologías de la base pulmonar o del hemiabdomen superior. ${ }^{4}$ Sin embargo, puede ocurrir que no sea posible diferenciar por imágenes entre la eventración focal y hernia diafragmática, sobre todo si hay un saco pleural con la hernia, o entre eventración completa y parálisis diafragmática $^{11-13}$.

Hernia diafragmática: Imágenes multiplanares permiten la clarificación de los casos dudosos y demostrar anomalías asociadas. Se puede visualizar el defecto y hacer el diagnóstico diferencial con eventración ${ }^{4,11-13}$ (Figura 18).

Lesiones traumáticas: Las reconstrucciones multiplanares con la TC son útiles en el diagnóstico de ruptura diafragmática aguda, con una sensibilidad, especificidad y precisión de 78\%, 100\% y $88 \%$ para el lado izquierdo y del $71 \%, 100 \%$ y $70 \%$ para el lado derecho, respectivamente. La presencia de signos de desgarro del diafragma en la TC, especialmente combinados, es un buen predictor de lesión diafragmática. La RM puede ser utilizada en pacientes más estables ${ }^{4}$.

Lesiones tumorales: El rol de las imágenes es demostrar el lugar de origen, la extensión del tumor y la afectación de otros órganos. Pero en el caso de los tumores diafragmáticos es un desafío para las imágenes determinar su exacto origen. El hígado, el pericardio, el pulmón, el bazo y el

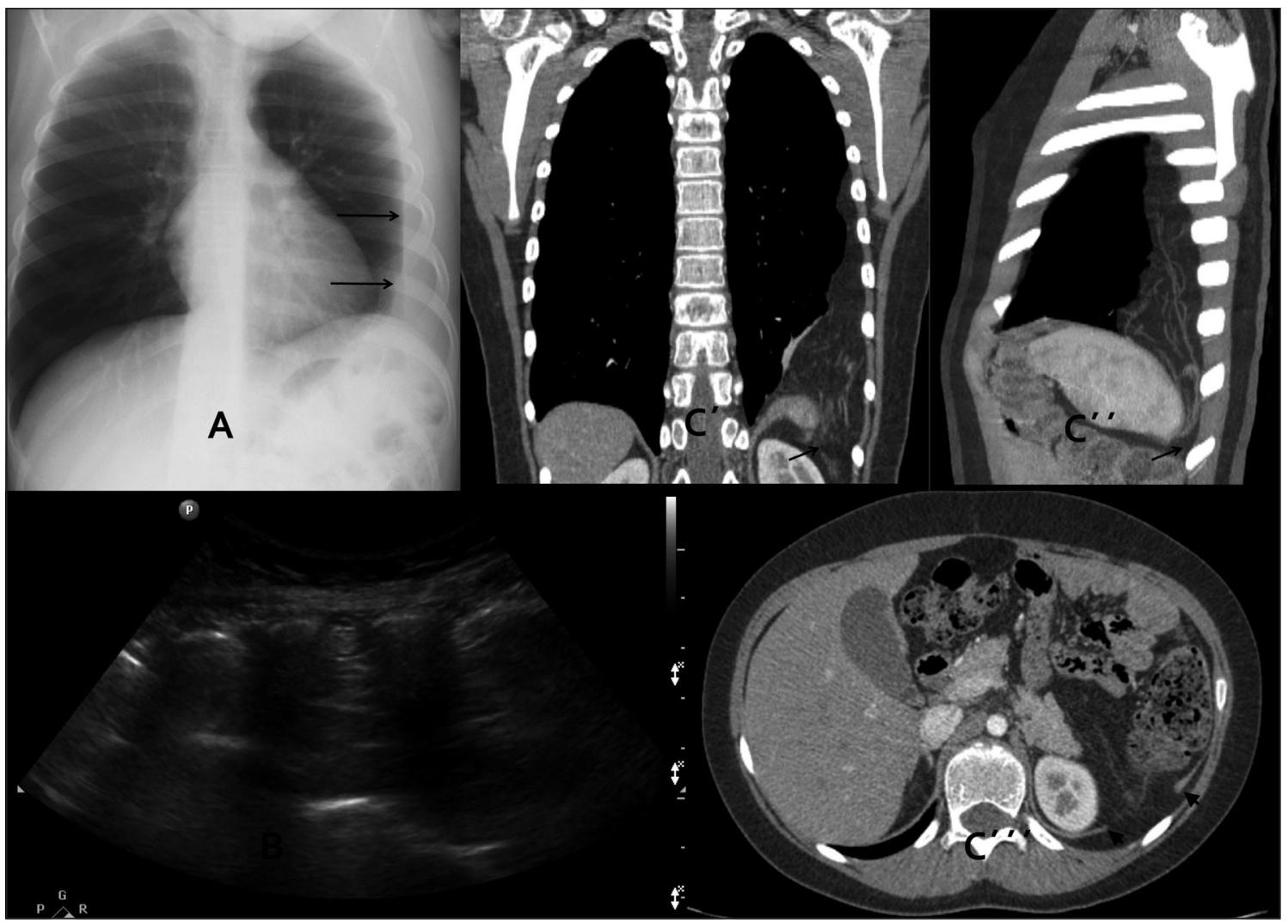

Figura 18. Niña de 9 años con derrame pleural izquierdo persistente. Toracocentesis negativas. a: RxTx AP muestra opacidad triangular periférica izquierda, de baja densidad, de base diafragmática (flechas horizontales); b: US de tórax muestra que se trata de una masa sólida inespecífica. (C'-C'-C'”) TC en los planos coronal, sagital y axial muestra un defecto posterior del diafragma (cabezas de flechas) por el cual se ha deslizado el epiplón (flechas oblicuas). Concordante con Hernia Diafragmática Congénita tipo Bochdalek. 

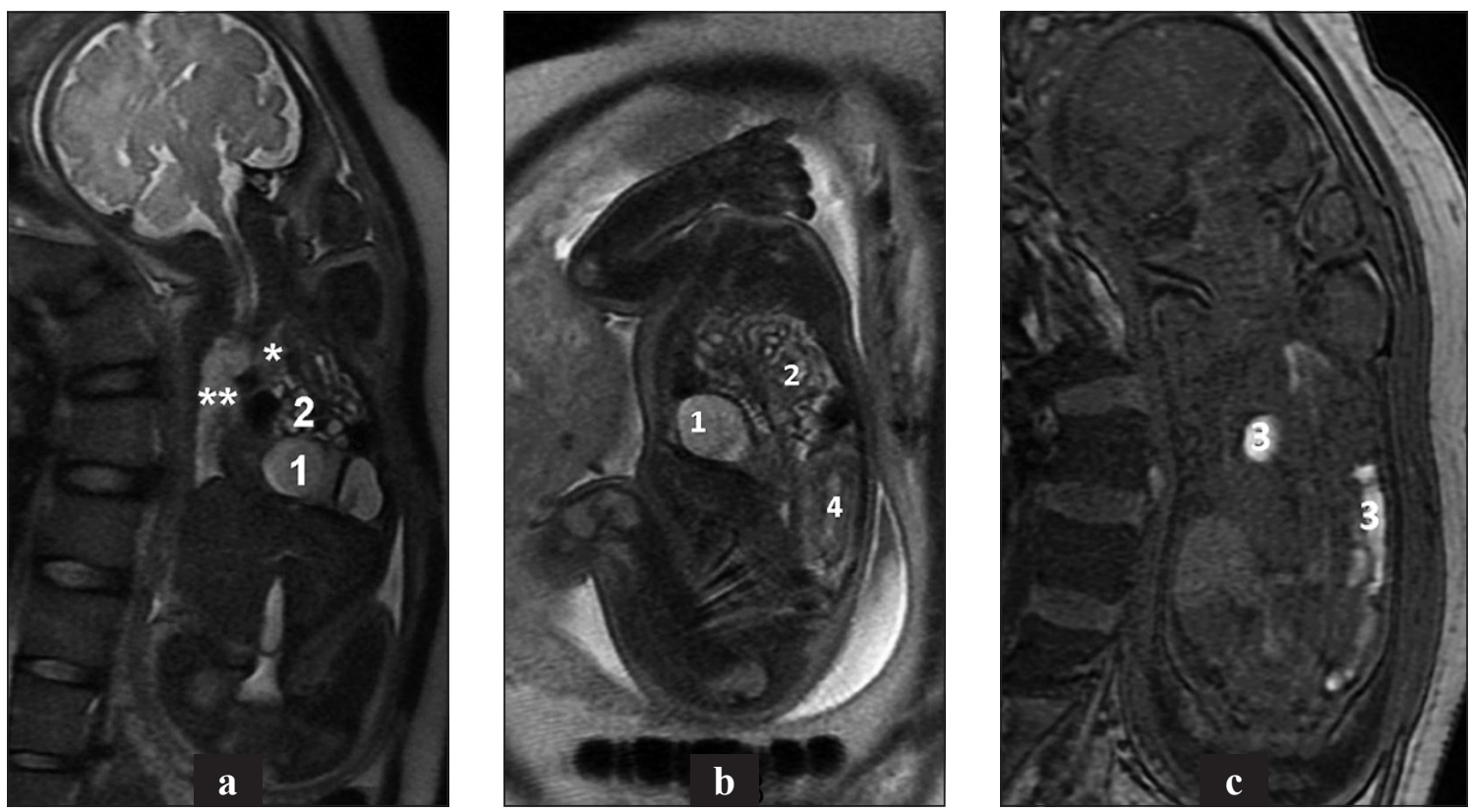

Figura 19 a-c. RM fetal. Feto de 34 semanas, con hernia diafragmática izquierda tipo Bochdalek. a: T2 coronal. b;T2 sagital, muestran que el estómago (1), asas intestinales (2), el colon (3) y el riñón izquierdo (4) están desplazados al tórax a través de un defecto diafragmático posterior izquierdo. Hay disminución de volumen del pulmón izquierdo (*) y menor volumen del pulmón derecho $(* *)$. c: T1 coronal muestra que parte del colon con meconio, que brilla en el T1 (3), forma parte del contenido de la hernia.

páncreas pueden ser erróneamente etiquetados como los sitios de origen. Incluso puede suceder que el uso de todas las modalidades de imágenes no ofrezcan una demostración clara del origen del tumor diafragmático ${ }^{4}$.

\section{RM fetal (RMF) en el estudio de la hernia diafragmática congénita (HDC)}

El diagnóstico prenatal de HDC es con US. La RMF es complementaria, ante limitaciones del US, cuando se vaya a realizar terapia intrauterina y para tomar conductas postnatales inmedia$\operatorname{tas}^{12,14}$

La RMF tiene un rol diagnóstico, al visualizar las vísceras abdominales en la cavidad torácica. (Figura 19). Sin embargo, su principal rol es pronóstico, ya que permite evaluar la hipoplasia pulmonar, lo que trasciende en el riesgo de insuficiencia respiratoria post natal ${ }^{11,12,14}$.

\section{Recomendaciones}

Ante la necesidad de evaluación de la motilidad diafragmática:

- La fluoroscopía sigue siendo un buen método para evaluar motilidad, más aún sí se dispone de videofluoroscopía.
- Sugerimos el uso de US en recién nacidos, niños que van a requerir más de una evaluación y niños en la Unidades de Cuidados Intensivos.

- La RM en nuestro medio aún es futuro y tiene el inconveniente de la anestesia.

- El diagnóstico de hernias hiatales se continúa haciendo con estudios contrastados del tubo digestivo.

En el estudio por imágenes de las hernias diafragmáticas congénitas:

- El diagnóstico es en la mayoría de los casos prenatal con US.

- La RMF tiene rol diagnóstico y pronóstico.

- La radiografía simple postnatal es diagnóstica.

Las modalidades multiplanares se deben reservar para: casos de hernias complejos o dudosos y que se requiera un buen detalle anatómico, y para el estudio del trauma diafragmático y lesiones tumorales.

\section{Bibliografía}

1.- http://www.ncbi.nlm.nih.gov/mesh/68003964

2.- WHITBOURNE S K. Diaphragmatic parálisis in the newborn. In: UpToDate, Basow, DS (Ed), UpToDate, Waltham, MA, 2009.

3.- SKANDALAKIS J. Diaphragm. En: Skandalakis' 
Surgical Anatomy (2004) chm. McGraw-Hill's. Access Surgery. Chapter 8 .

4.- CHAVHAN G B, BABYN P S, COHEN R A, LANGER J C. Multimodality Imaging of the Pediatric Diaphragm: Anatomy and Pathologic Conditions. RadioGraphics 2010; 30: 1797-817.

5.- MOËNNE K, ORTEGA X. Tórax normal. En: Diagnóstico por imágenes del tórax pediátrico. Ediciones Journal 2005. Primera Edición. Cap 3, pp 50-1.

6.- EPELMAN M, NAVARRO O M, DANEMAN A, MILLER S F. M Mode sonography of diaphragmatic motion: description of technique and experience in 278 pediatric patients. Pediatr Radiol 2005; 35: 661-7.

7.- PÉREZ L, RODRÍGUEZ J, UBILLA C, DÍAZ C, ARROYO R, AVARIA M, et al. Ultrasonido: una alternativa en la evaluación del diafragma en niños con distrofia muscular de Duchenne. Rev Chil Radiol 2011; 17: $37-43$.

8.- RICCABONA M, SORANTIN E, RING E. Application of M-mode sonography to functional evaluation in pediatric patients. Eur Radiol 1998; 8: 1457-61.

9.- RICCABONA M. Ultrasound of the chest in children. Eur. Radiol 2008; 18: 390-9.
10.- GARRIDO P, ACASTELLO E. Eventración diafragmática en edad pediátrica. Rev Med Clin Condes 2009; 20: 776-81.

11.- TAYLOR G, ATALABI O, ESTROFF J. Imaging of congenital diaphragmatic hernias. Pediatr Radiol 2009; 39: 1-16.

12.- HEDRICK H L. Congenital diaphragmatic hernia: Prenatal diagnosis and management. In: UpToDate, Basow, DS (Ed), UpToDate, Waltham, MA, 2011.

13.- MOËNNE K, ORTEGA X. Tórax neonatal y malformaciones congénitas. En: Diagnóstico por imágenes del tórax pediátrico. Ediciones Journal 2005. Primera Edición. Cap 8, pp 167-9.

14.- AMIM B, WERNER JN H, DALTRO P, ANTUNES E, FAZECAS T, RODRIGUES L, et al. The value of fetal ultrasonography and magnetic resonance imaging in the assessment of diaphragmatic hernias. Rev Bras 2008; 41: 1-6.

15.- KOLAR P, NEUWIRTH J, SANDA J, SUCHANEK V, SVATA Z, VOLEJNIK J, et al. Analysis of diaphragm movement during tidal breathing and during its activation while breath holding using MRI synchronized with spirometry. Physiol Res 2009; 58: 383-92.

Correspondencia a:

Lizbet Pérez M.

Radióloga Pediatra.

Hospital de Niños Roberto del Río.

Santiago de Chile.

E-mail: lizbet.perez@gmail.com 